\title{
ESTUDIO
}

\section{LAS PALABRAS SE APRENDEN GRADUALMENTE MEDIANTE EXPOSICIONES MÚLTIPLES*}

\begin{abstract}
Steven A. Stahl
El texto que se reproduce a continuación ilustra cómo se llega a tener un conocimiento completo y flexible de un vocablo. Se trata de una breve adaptación autorizada del libro de Steven Stahl, Vocabulary Development, de la serie From Reading Research to Practice: A Series for Teachers (Brookline Books, 1999), que viene a complementar el artículo de E. D. Hirsch, “La Comprensión Lectora Requiere Conocimiento de Vocabulario y del Mundo” que se publica en esta edición de Estudios Públicos.
\end{abstract}

Steven A. Stahl. Fue profesor de currículo e instrucción en la Universidad de Illinois, Urbana-Champaign, e investigador del Center of the Study of Reading y del National Reading Research Center en los Estados Unidos, tras haber sido profesor de lectura en escuelas de instrucción primaria en Nueva York y Maine. Escribió importantes artículos de investigación sobre la lectura y la enseñanza de la lectura.

* Título original en inglés: "How Words Are Learned Incrementally Over Multiple Exposures”. Apareció originalmente en American Educator, primavera 2003, junto al artículo de E. D. Hirsch "Reading Comprehension Requires Knowledge —of Words and the World: Scientific Insights into the Fourth-Grade Slump and the Nation's Stagnant Comprehension Scores”. Su reproducción en esta edición de Estudios Públicos cuenta con el permiso de American Educator, revista trimestral de la American Federation of Teachers, AFL-CIO, y de Brookline Books, Brookline MA 02445.

Traducción al castellano de Luis Felipe Correa-Reyes para Estudios Públicos. 


\section{$\mathrm{V}_{\mathrm{i}}$}

ivimos en un mar de palabras. La mayoría de las palabras que conocemos nos son o muy familiares o, al menos, tenemos algún grado de familiaridad con ellas. Normalmente cuando nos encontramos con una palabra que no conocemos nos la saltamos, especialmente si la palabra no es necesaria para comprender el sentido de lo que estamos leyendo (Stahl, 1991). Pero algo recordamos de las palabras que nos saltamos. Este algo podría ser donde la vimos, cierta parte del contexto en que apareció u otro aspecto. Esta información está en la memoria, pero la memoria no es lo suficientemente fuerte como para que nuestra mente consciente pueda acceder a ella. A medida que nos topamos de manera reiterada con una palabra, acumulamos más y más información sobre ella hasta que tenemos una vaga noción de lo que "significa”. A medida que conseguimos más información, podemos definir esa palabra. De hecho, McKeown, Beck, Omanson y Pople (1985) observaron que cuatro encuentros con una palabra no mejoraban de manera significativa la comprensión de lectura, pero doce encuentros sí lo hacían.

¿Qué sucede cuando alguien ve una palabra por primera vez en un libro? Consideremos el siguiente párrafo de la publicación Atlantic Monthly:

Estados Unidos se encuentra permanentemente en campaña electoral, lo que sumado a otros aspectos de la política electoral tiene una consecuencia crucial, aunque poco advertida, para el funcionamiento de la democracia estadounidense. Dicho en forma simple, el sistema de elecciones estadounidense coloca a los políticos en una posición muy vulnerable. En forma individual y colectiva ellos son más vulnerables, durante más tiempo, a las vicisitudes de la política electoral que los políticos de cualquier otro país democrático. Porque están en una situación más vulnerable, dedican una mayor parte de su tiempo a actividades electoralistas, y con mayor frecuencia ejercen el cargo influenciados por consideraciones electorales. (King, 1997)

Aunque anteriormente había visto la palabra vicisitudes, no sabía su significado. Del contexto uno puede extraer una imagen general de lo que significa, algo así como “sucesos fortuitos” (serendipitous happenings). Mi Random House Dictionary (1978) los define como “circunstancias que inesperadamente cambian, como por fortuna”, así que estuve bastante cerca en mi suposición.

Cuando nos encontramos por primera vez con una palabra, la información sobre su ortografía (o deletreo) se conecta con la información del 
contexto, de modo que después de una exposición a la palabra se podría tener una noción general del contexto en que apareció ("tiene algo que ver con...”), o recordar el contexto específico ("recuerdo haberla visto en un manual del automóvil”), pero no se tendrá una noción generalizable de su significado. Dale y O’Rourke (1986) hablan de cuatro “niveles” de conocimiento de una palabra:

1. Nunca antes la había visto.

2. Había oído hablar de ella, pero no sé lo que significa.

3. La reconozco en ese contexto, tiene que ver con...

4. Sé lo que significa.

Al toparnos habitualmente con una palabra en cierto contexto, algo de la información que se recuerda se verá reforzado. La información que se superpone en los distintos encuentros con la palabra es la importante. El resto de la información será olvidado. La información olvidada tiene un carácter más incidental. Como consecuencia de repetidas exposiciones a la misma palabra, algunas conexiones se consolidan debido a que esa información se encuentra en diferentes contextos, convirtiéndose en la manera en que la palabra se “define”.

Consideremos la palabra vicisitudes en el contexto anterior. Con toda probabilidad, el concepto de vicisitudes se conectará con otros conceptos del contexto, tales como "políticos”, "política electoral” o, posiblemente, con la totalidad del contexto en que se presentó. Debido a la sintaxis, sabemos que vicisitudes no significa directamente "política”, pero es una característica de la política. Al encontrarnos una y otra vez con la palabra, la asociaremos con otros conceptos, posiblemente con "romance" o con “conseguir un trabajo”. (O como la madre de uno de mis estudiantes le repetía en diversas ocasiones mientras crecía: “Guárdate de las vicisitudes de la vida”.) Éstos se convierten en los componentes más fuertes del concepto, como los que se pudieran presentar en la definición de un diccionario (McKeown, 1991). Si las conexiones con otros conceptos no se repiten, éstas podrían perder importancia. Dada la esencia del significado de la palabra vicisitudes, el hecho de que el tema del ensayo sea la política resulta accidental, y probablemente será olvidado si se repiten las exposiciones a esa palabra en otros contextos.

A medida que una persona se topa de modo reiterado con la palabra, el significado de la palabra crece a una tasa relativamente constante, depen- 
diendo de las características del contexto. Esto es, manteniendo todos los factores constantes salvo el contexto, encontramos que la ganancia absoluta en conocimiento de una palabra es la misma cuando se trata de un vocablo totalmente desconocido que cuando se trata de un vocablo del que ya se tiene un conocimiento parcial (Schwanenflugel, Stahl, y McFalls, 1997). En efecto, observamos que a partir de una sola lectura los estudiantes aumentaron su conocimiento de una palabra en la misma proporción, ya fuera que supieran o no algo de la palabra al comenzar la lectura. Así, al parecer, el conocimiento del vocabulario crece gradualmente desde la primera vez que una persona se expone significativamente a una palabra hasta que llega a tener un conocimiento completo y flexible de la misma.

No siempre se necesita conocer del todo una palabra para entenderla en su contexto, o aun para contestar correctamente una pregunta en una prueba. Los adultos tienen una cantidad sorprendente de información sobre palabras parcialmente conocidas y supuestamente desconocidas. Aun cuando las personas digan no haber visto antes cierta palabra, en una prueba en que se les pide elegir la oración en la que fue utilizada correctamente la palabra, o discriminar entre un sinónimo correcto e incorrecto, acertarán más allá de la casualidad o la suerte (Durso y Shore, 1991). Esto sugiere que las personas tienen cierto conocimiento, incluso de palabras que dicen desconocer, y que este conocimiento se podría utilizar para hacer las discriminaciones gruesas que tienen que ver con el significado de una palabra. Curtis (1987) observó que personas que decían tener solamente un conocimiento parcial del significado de una palabra ("la he visto antes") elegían la respuesta correcta en preguntas de selección múltiple.

Cuando una persona "conoce" una palabra, sabe más que la mera definición de la palabra: también sabe cómo funciona esa palabra en diversos contextos. Por ejemplo, la definición del verbo fumar (smoke) puede ser algo así como "aspirar y exhalar el humo de (un cigarrillo, etc.)" (Random House Dictionary, 1978). Sin embargo, el verbo fumar describe con nitidez diferentes acciones en las siguientes oraciones:

(a) Él fumó un cigarrillo.

(b) El psicólogo fumaba su pipa.

(c) El hippie se fumó un cigarrillo de marihuana.

(d) El niño de 13 años fumó su primer cigarrillo.

Todas ellas caben en la definición general de la palabra fumar, pero las acciones varían desde una acción típica del fumar en (a), a "dar una pipada” en (b), a una aspiración más profunda y más larga en (c), hasta una 
aspiración seguida de tos y ahogo en (d). Los niños no pueden conseguir esta información a partir de una definición de diccionario. En su lugar, necesitan toparse con la palabra en muchos contextos distintos para ver cómo el significado de la palabra cambia y se desplaza.

Así pues, para entender la palabra en la oración (d) necesitamos saber que los niños de trece años son por lo general fumadores principiantes y que el fumar puede provocar tos si no se está acostumbrado a fumar. Algunas palabras se relacionan con un solo ámbito del conocimiento, tal como dharma o bauprés. Para entender dharma, uno debe comprender por lo menos algunos conceptos básicos del hinduismo o el budismo. Para entender bauprés, se debe saber algo sobre navegación a vela. Estas palabras están unidas de tal modo a ámbitos específicos del conocimiento que no pueden ser definidas fuera de ellos. (Algunos, e. g., Johnston, 1984, han utilizado pruebas de vocabulario para medir el conocimiento en distintos ámbitos.) La mayoría de las palabras pueden ser utilizadas en múltiples áreas, pero tienen significados diferentes dentro de esas áreas. La palabra obligación, por ejemplo, tiene una serie de significados relacionados, dependiendo de si la obligación es moral o se trata del pago de un préstamo, y así sucesivamente. Anderson y Nagy (1991) sostienen que las palabras son polisémicas, que ellas contienen grupos de significados relacionados y no un solo significado fijo. Estos significados se parecen entre sí. Consideremos la palabra dar en los siguientes contextos diferentes (Anderson y Nagy, 1991):

- Juan le dio cinco dólares a Pedro.

- Juan le dio un beso a María.

- El doctor le dio un remedio al niño.

- La orquesta dio un espectáculo maravilloso.

Todos estos contextos implican una cierta clase de transmisión, donde están presentes un dador, un receptor y algo, tangible o intangible, que se da. Pero el acto de dar es radicalmente diferente en cada caso.

Conocer de manera completa y con flexibilidad una palabra implica comprender el significado básico de la palabra y cómo éste cambia en distintos contextos. Para conocer una palabra no sólo necesitamos tener conocimiento definicional, o conocimiento de la relación lógica en la que se inscribe la palabra, por ejemplo la categoría o clase a la que pertenece la palabra (e. g., sinónimos, antónimos, etc.). Ésta es información similar a la 
que aparece en una definición de diccionario. Adicionalmente, también necesitamos comprender cómo se adapta el significado de la palabra a diversos contextos. He denominado a esto conocimiento contextual, puesto que viene de la exposición a una palabra en contextos. Esto implica exposición a la palabra en contextos múltiples desde perspectivas diferentes. Es dable suponer que los niños expuestos a una palabra en contextos múltiples, incluso sin instrucción, aprenderán más sobre esa palabra que los estudiantes que la ven en un solo contexto (Nitsch, 1978; Stahl, 1991).

\section{REFERENCIAS}

Anderson, R. C., \& W. E. Nagy (1991): “Word Meanings”. En R. Barr, M. L. Kamil, P. Mosenthal, \& P. D. Pearson (eds.): Handbook of Reading Research, Vol. II. White Plains, N. Y.: Longman.

Curtis, M. E. (1987): “Vocabulary Testing and Vocabulary Instruction”. En M. G. McKeown \& M. E. Curtis (eds.), The Nature of Vocabulary Acquisition. Hillsdale, N. H.: Erlbaum.

Dale, E., \& J. O’Rourke (1986): Vocabulary Building. Columbus, Ohio: Zaner-Bloser.

Durso, F. T., \& W. J. Shore (1991): “Partial Knowledge of Word Meanings”. En Journal of Experimental Psychology: General, 120, pp. 190-202.

Johnston, P. (1984): "Prior Knowledge and Reading Comprehension Test Bias”. En Reading Research Quarterly, 19, pp. 219-239.

King, A. (1997): “Running Scared”. En Atlantic Monthly, 279 (1), pp. 41-56.

McKeown, M. G. (1991): “Learning Word Meanings from Dictionaries”. En P. Schwanenflugel (ed.), The Psychology of Word Meanings. Hillsdale, N. Y.: Lawrence Erlbaum Associates.

McKeown, M. G., I. L. Beck, R. C. Omanson \& M. T. Pople (1985): "Some Effects of the Nature and Frequency of Vocabulary Instruction on the Knowledge of Use of Words”. 20, pp. 522-535.

Nitsch, K. E. (1978): Structuring Decontextualized Forms of Knowledge. Inédito. Ph.D., Vanderbilt. Random House Dictionary (1978): New York: Random House.

Schwanenflugel, P. J., S. A. Stahl, \& E. L. McFalls (1997): Partial Word Knowledge and Vocabulary Growth during Reading Comprehension (Research Report No. 76). University of Georgia, National Reading Research Center.

Stahl, S. A. (1991): "Beyond the Instrumentalist Hypothesis: Some Relationships between Word Meanings and Comprehension”. En P. Schwanenflugel (ed.), The Psychology of Word Meanings, pp. 157-178. Hillsdale, N. H.: Lawrence Erlbaum Associates. 